\title{
Türkiye'de Aletli Dalış Konusunda Son 20 Yılda Yazılan Makalelerin Alanyazın Taraması
}

\author{
DOI: 10.26466/opus. 972132
}

\author{
Alper Bozkurt* \\ * Doç. Dr., Adana Alparslan Türkeş Bilim ve Teknoloji Üniversitesi, Adana/Türkiye \\ E-Posta: abozkurt@atu.edu.tr \\ ORCID: $\underline{0000-0002-3725-2493}$
}

Öz

Aletli dalış dünya genelinde pek çok insanın hobi olarak yaptığı aktivite sporlarından birisidir. Geçmişi eski dönemlere kadar gitse de sportif amaçlı yapılan dalışlar son yüzyılda ivme kazanmıştır. Dünya genelinde farklı dalıs organizasyonları bu konuda eăitim ve sertifika vermektedirler ve dünyada 6 milyon civarı sertifikalı dalgıç olduğu tahmin edilmektedir. Bu dalgıçların önemli bir kısmı aletli dalış amacıyla dünya genelindeki tanınmış dalış bölgelerine seyahat etmekte, bu sayede gittikleri ülkelerin ekonomisine ciddi katkılarda bulunmaktadırlar. Dünyaca ünlü kayıtlı tanınmış dalış bölgeleri bulunmamakla beraber ülkemiz bu konuda iyi bir potansiyele sahiptir. Buna rağmen ülkemizin bu mevcut potansiyeli yeterince kullanamadığı düşünülmektedir. Bu çalışma dünya genelinde aletli dalış konusunda bazı temel bilgiler ve rakamları sunmanın yanında ülkemizdeki durum hakkında da kısaca bilgi sunmayı hedeflemektedir. Özelde ise, turizm açısından böylesine önemli ve katma değer oluşturabilecek bir konuda ülkemizde son yirmi yılda yapılan çalışmaları bir araya toplayıp okuyucuya sunarak bir bakıma akademinin konuya verdiği (veya vermediği) önemi göstermeyi amaçlamaktadır.

Anahtar Kelimeler: Aletli Dalış, Scuba, Dünyada ve Türkiye'de Aletli Dalış, Aletli Dalış Organizasyonları, Türkiye'deki Aletli Dalış Üzerinde Alanyazın Taraması. 


\title{
Scuba Diving Literature Review in Turkey for the Past 20 Years
}

\begin{abstract}
Scuba diving is one of the activity sports that worldwide many people pursue as a hobby. Despite having roots in ancients times, it is fair to claim that sports diving as practised today has evolved recently. There are different organisations that give training and certify divers around the world. It is estimated that there are about 6 million certified divers in the world. Some of these divers travel to the world's famous scuba sites, financially contributing to the economies of the countries they visit. Although not having worldwide famous sites, Turkey has a great potential on the matter. Despite having a great potential, it is fair to state that Turkey cannot fully use these resources. This study aims to present some basic facts about scuba diving, along with providing information about the status of scuba diving in Turkey. In particular, it targets to present last 20 years of academic research on the subject, by doings so it also tries to establish the importance given to the scuba diving by Turkish academia.
\end{abstract}

Keywords: Scuba Diving, Scuba, Scuba Diving in the World and in Turkey, Scuba Diving Organisations, Literature Review on Scuba Diving in Turkey. 


\section{Giriş}

Sualtı dünyası öteden beri insanların dikkatini çekmiştir. Denizler ve gizemli deniz canlıları hakkında anlatılan efsaneler dışında insanoğlu sualtına inerek denizin derinliklerini bir şekilde keşfetmeye çalışmıştır. Serbest dalış tarih boyunca gerek spor ve eğlence amaçli, gerekse ticari maksatlı farklı şekillerde yapılagelmiştir. Kısa süreli iniş çıkışlar şeklinde olsa da sünger, midye, istiridye, çeşitli balık ve deniz canlıları avcılı̆̆ı gibi amaçlarla serbest dalış asırlardır yapılmakta ve günümüzde de tercih edilmektedir. Serbest dalışın en önemli kısıtlamalarının başında sualtında kalma süresinin azlığı ve inilebilecek derinliğin sınırlı olması gelmektedir. Öte yandan, sualtı ve deniz dibine inerek suyun altında uzun süre kalma çabalarının Milattan öncesine kadar gittiği yönünde kayıtlar bulunsa da (Sofular, 1992) modern dönemlerde aletli dalışla ilgili faaliyetlerin ikinci dünya savaşı sonrasında hız kazandığını söylemek mümkündür. Daha önceleri sualtı çanları veya dalgıçlar arasında "nargile" diye de adlandırılan yüzeye hortumla bağlı, hareketleri ve sualtında çalışmayı ciddi şekilde kısıtlayan alternatifler sonrası, Fransızların belgesellere konu olan efsane ismi Jacques-Yves Cousteau ve ekibinin 1940'larda geliştirdiği ve "Aqua-Lung" ismini verdikleri bağımsız ünite ile profesyonel ve amatör sualtı dalgıçlı̆ğ ivme kazanmıştır (Matson, 2009). Aqua-Lung dalgıcın üzerinde taşıdığı bir tüp ve buna bağlı hava alıp-vermesini sağlayan bir düzenekten oluşmaktadır. Genel kanının aksine, dalgıçlar sualtında oksijen değil dalış kompresörleri sayesinde filtre sistemiyle toz gibi elementlerden büyük oranda arındırılıp basınçla bu amaçla yapılmış dalış tüplerine doldurulan normal havayı teneffüs ederler. Cousteau'nun dalışta çı̆̆ır açan Aqua-Lung sistemi bazı değişikliklere uğramış olsa da amatör ve profesyonel dalgıçların günümüzde kullandıkları sistem büyük oranda aynıdır, hatta orijinal sistem birebir şekilde sualtı fotoğrafçılığı ve film çekimlerinde tercih sebebi olarak aynen kullanılmaktadır.

İngilizce "Self Contained Underwater Breathing Apparatus" kelimelerinin kısaltması olarak kullanılan "Scuba" ve "Tüplü Dalış" olarak da adlandırılan aletli dalış günümüzde pek çok insanın boş zaman geçirmede tercih ettiği spor dallarından birisi olmaktadır. Genel anlamıyla tanımlamak gerekirse, sportif dalış, en fazla dalınabilecek derinlik 
gibi belirli kısıtlamaları bulunan ve farklı seviyede alınan eğitimler sonrası kişinin gelir getirme amacıyla yapmadığı amatör dalışları ifade etmektedir. Yapılan araştırmalar 2021 yılı rakamlarına göre Kuzey Amerika'da aktif bröveli dalgıç (herhangi bir kurumdan bu konuda eğitim almış ve halen fiili olarak aletli dalış yapan) sayısını 2,6 milyon; Avrupa'da 3,5 milyon; dünyada ise 6 milyon olarak tahmin etmektedir (Scubanomics, 2021). Dünya genelinde ise aletli dalış eğitimleri Kuzey Amerika'nın öncülük ettiği PADI (Professional Association of Diving Instructors), NAUI (National Association of Underwater Instructors) gibi profesyonel kuruluşlar yanında Fransızların CMAS (Confédération Mondiale des Activités Subaquatiques), İngilizlerin BSAC (British Sub Aqua Club) ve ülkemizin TSSF (Türkiye Sualtı Sporları Federasyonu) gibi ülke genelindeki resmi veya yarı resmi kuruluşlar tarafından verilmektedir. Dünya genelinde en fazla dalış eğitmeni ve sportif dalgıç yetiştiren PADI, 1967 yılında kurulduğundan beri toplamda 27 milyondan fazla çeşitli seviyelerde dalış sertifikası düzenlemiş ve 137.000 'den fazla üyesi bulunan, 186 ülkede 6.600 'den fazla dalış merkezi olan, bölgesel ofisleri kanalıyla faaliyetlerini sürdüren devasa bir kuruluştur. PADI'de bu amaçla sırasıyla Scuba Diver, Open Water Scuba Diver, Advanced Diver ve Rescue Diver kursları ile Open Water Diver sonrası alınabilecek Dry Suit Diver, Deep Diver gibi çeşitli Speciality Diver kursları bulunmaktadır (PADI, 2021).

Dünyanın pek çok ülkesinde dalgıçları cezbeden farklı özelliklerde dalış bölgeleri bulunmaktadır (Ince ve Bowen, 2011). Sıralama farklı kriterler dikkate alındığında değişiklik gösterse de ilk 10 sıraya giren dalış bölgeleri Avustralya Townswill'deki SS Yongala batığı, Malezya Sipadan'daki Baraküda bölgesi, Avustralya North Horn açıklarındaki sualtı kayalıkları, Tayland Surin Adaları civarındaki Richeliue sualtı kayalıkları, Endonezya Bali'deki USS Liberty batığı, Avustralya Büyük Mercan Kayalıklarındaki orfoz yuvaları, Avustralya Exmouth'daki Deniz Kuvvetlerine ait liman ve körfez özellikle köpekbalıkları ve diğer zengin sualtı canlıları zenginliği, Endonezya Nusa Penida/Nusa Lembongan civarındaki "mola mola" balıklarına yılın belirli dönemi evsahipliği yapan Kristal Limanı, yine Endonezya Komodo adaları civarındaki Batu Bolong'daki çeşitli sualtı canlıları ve Tayland Similan Adaları civarında yer 
alan Elephant Head sualtı kayalıkları sayılabilir (divezone.net, 2021). Tablo 1 bu listeyi içermektedir.

Tablo 1. Dünyanın ilk 10 Dalış Bölgesi (divezone.net)

\begin{tabular}{llll}
\hline Sıra No & Ülke & Dalış Bölgesi & Özelliği \\
\hline 1 & Avustralya & Townswill & Batık \\
2 & Malezya & Sipadan & Baraküdalar \\
3 & Avustralya & North Horn & Sualtı Kayalıkları \\
4 & Tayland & Surin Adaları & Sualtı Kayalıkları \\
5 & Endonezya & Bali & Batık \\
6 & Avustralya & Büyük Mercan Kayalıkları & Orfoz Yuvaları \\
7 & Avustralya & Exmouth & Köpekbalıkları \\
8 & Endonezya & Nusa Penida/Lembongan & Mola Mola Balıları \\
9 & Endonezya & Komodo Adaları & Çeşitli Sualtı Canlıları \\
10 & Tayland & Similan Adaları & Sualtı Kayalıkları \\
\hline
\end{tabular}

Tablodan da görüleceği şekilde dünyadaki ilk 10 dalış bölgesi listesinde Avustralya ülke olarak 4 bölge ile birinci, Endonezya 3 bölge ile ikinci, Tayland 2 bölge ile üçüncü ve Malezya 1 bölge ile dördüncü sırada yer almaktadir.

Türkiye'deki durumu incelediğimizde ise, ziyaretçilerin edindikleri tecrübe sonrası internet üzerinden yaptıkları değerlendirme sonuçlarına göre ilk 10 dalış bölgesi arasında Fethiye Akvaryum Koyu, Bodrum Büyük Resif sualtı kayalıkları, Kaş Uçan Balık bölgesi, Çanakkale Saros körfezi, Ayvalık'taki farklı resifler ve mercan kayalıkları, İstanbul Sivriada "67 taşı" olarak adlandırılan bölge, Datça özellikle köpekbalığı ve yunusları gözlemlemek için, Marmaris'te bulunan batık, antik kalıntı, resif gibi farklılıklar içeren dalış bölgeleri, Gökova, Kocadağ bölgesi gerek sualtı görüş mesafesinin çok uzun olduğu billur gibi denizi, gerekse orfoz ve lahoz balıkları gibi zengin yaşam türlerini barındırması ve son olarak da yine çok çeşitli bir sualtı canlıları yelpazesine ev sahipliği yapan Kalkan açıları sayılabilir (gezimanya.com).

Tablo 2. Türkiye'nin ilk 10 Dalış Bölgesi (gezimanya.com)

\begin{tabular}{llll}
\hline Sıra No & İl/İçe & Dalış Bölgesi & Özelliği \\
\hline 1 & Fethiye & Akvaryum Koyu & Çeşitli Sualtı Canlıları \\
2 & Bodrum & Büyük Resif & Sualtı Kayalıkları \\
3 & Kaş & Uçan Balık & Batık \\
4 & Çanakkale & Saros Körfezi & Batık \\
5 & Ayvalık & Ayvalık & Mercan Kayalıkları \\
6 & İstanbul & Sivriada & Çeşitli Sualtı Canlıları \\
7 & Datça & Datça & Köpekbalıkları
\end{tabular}




\begin{tabular}{llll}
8 & Marmaris & Marmaris & Batık \\
9 & Gökova & Kocadağ & Çeşitli Sualtı Canlıları \\
10 & Kalkan & Kalkan & Çeşitli Sualtı Canlıları \\
\hline
\end{tabular}

Tablo 2 incelendiğinde ilk 10'a giren en fazla dalış bölgesi bulunan ilimiz 5 bölgeyle Muğla olmakta, ardından ikişer bölgeyle Antalya ve Çanakkale gelmekte, en sonunda da 1 dalış bölgesiyle İstanbul yer almaktadır.

Türkiye Sualtı Sporları Federasyonu'na kayıtlı dalış merkezleri sayılarının illere göre dağılımı incelendiğinde alfabetik sıraya göre Ankara'da 5, Antalya'da 22, Aydın'da 2, Balıkesir'de 3, Bursa'da 3, Çanakkale'de 5, Edirne'de 1, Eskişehir'de 1, Isparta'da 1, İstanbul'da 18, İzmir'de 14, Kocaeli'de 4, Manisa'da 1, Mersin'de 5, Muğla'da 13, Sakarya'da 2, Samsun'da 1, Tekirdağ'da 1, Trabzon'da 1 ve Van'da 1 olmak üzere toplam 20 ilde 107 dalış merkezi bulunduğu görülmektedir (tssf.gov.tr).

Tablo 3. Türkiye'nin illere göre dalış merkezleri sayıları (tssf.gov.tr)

\begin{tabular}{lll}
\hline Sira No & Il & Dalış Merkezi \\
\hline 1 & Ankara & 5 \\
2 & Antalya & 22 \\
3 & Aydın & 2 \\
4 & Balıkesir & 3 \\
5 & Bursa & 3 \\
6 & Çanakkale & 5 \\
7 & Edirne & 1 \\
8 & Eskişehir & 1 \\
9 & Isparta & 1 \\
10 & İstanbul & 18 \\
11 & İzmir & 14 \\
12 & Kocaeli & 4 \\
13 & Manisa & 1 \\
14 & Mersin & 5 \\
15 & Muğla & 13 \\
16 & Sakarya & 2 \\
17 & Samsun & 1 \\
18 & Tekirdağ & 1 \\
19 & Trabzon & 1 \\
20 & Van & 1 \\
\hline
\end{tabular}

Tablo 3 incelendiğinde illere göre en fazla dalış merkezi 22 merkezle Antalya olmakta, ardından 18 merkezle İstanbul, 14 merkezle İzmir, 13 merkezle Muğla, 5'er merkezle Ankara, Çanakkale ve Mersin, 4 merkezle Kocaeli, 3'er merkezle Balıkesir ve Bursa, 2'şer merkezle Aydın ve Sakarya, son olarak da 1'er merkezle Edirne, Eskişehir, Isparta, Manisa, Samsun, Tekirdağ, Trabzon ve Van illerimiz gelmektedir. Tablo 2 ve Tablo 3 karşılaştırıldığında dikkat çeken konu, ülkemizin en çok tercih edilen 
dalış bölgelerine sahip olan Muğla ilimizin dalış merkezi sayısına göre 4 . ilimiz olması, yine ilk 10 dalış bölgesi sıralamasında 1 bölgeyle en sonda yer alan İstanbul ilimizin ise en fazla dalış merkezi bulundurma sayısı dikkate alındığında 2. sırada yer almasıdır. Bu konuda yapılabilecek açıklama İstanbul'un ülkemizde en fazla nüfusa sahip bulunan il olması ve İstanbul bölgesi dalgıçlarının dalışlarını Muğla, Antalya gibi gerek iklim ve sezon, gerekse dalış bölgeleri açısından İstanbul'a göre daha uygun olan sahil kesimlerinde yapıyor olmalarıdır.

\section{Yöntem}

Bu çalışma TR Dizin'de taranan dergilerde son dönemde aletli dalış konusunda yazılan makalelerin tespiti, tasnifi ve bulunan sonuçların paylaşılmasını amaçlamaktadır. Bu amaçla yapılan araştırmada aletli dalış konusunda Ulakbim veri tabanına kayıtlı dergilerde TR Dizin arama motoru kullanarak 2000-2021 yılları arasında İngilizce ve Türkçe dillerinde yayınlanmış "dalış", "tüplü dalış” ve "aletli dalış" anahtar kelimeleri ile fen bilimleri ve sosyal bilimler alanlarında yapılan arama sonucunda, makalenin yayına hazırlandığ bulunmuştur. "Serbest dalış" veya "platform dalışı" gibi aletli dalışla bağlantısı olmayan konularda yapılan yayınlar dikkate alınmamıştır.

\section{Bulgular}

Aletli dalışla ilgili yapılan bütün bu açıklamalar ve Tablolar 1-3'de verilen rakamlar konunun turizm açısından önemini göstermesi yönünden önemlidir. Ülkemiz dünyadaki sayılı turizm destinasyonlarından olmasına rağmen aletli dalışta ilk 10 dalış bölgesi sıralamasına girememesinin nedeni olarak dalışa elverişli veya sıralamaya girecek kalitede dalış bölgeleri bulundurmamasından çok, belki de yeterince önem verilmeyip konu hakkında yeterli çalışma ve tanıtım yapılmadığından olabileceği düşüncesi ağır basmaktadır. Araştırmaya konu TR Dizin'de yayınlanan makalelerin çoğu son yıllarda yayınlanmış olmak kaydiyla 2 tanesi 2001, 1 tanesi 2008, 1 tanesi 2012, 3 tanesi 2018, 5 tanesi 2019 ve 3 tanesi de 2020 tarihlidir. Makalelerin yazıldıkları disiplin türleri 
incelendiğinde Tıp kökenli makale sayısının 7, Mühendislik kökenli (Bilgisayar ve Su Ürünleri Mühendisliği) 5 ve Sosyal Bilim kökenli (İşletme ve Turizm) 3 makale olduğu görülmektedir. Belirtilen bu makaleler kronolojik sıraya göre listelenmiştir.

Tablo 4. 2000-2021 Yilları arasinda TR Dizin'de Yayınlanan Makaleler

\begin{tabular}{|c|c|c|c|c|c|}
\hline Yazar ve Yil & Başlık & $\begin{array}{l}\text { Veri Toplama } \\
\text { Yöntemleri }\end{array}$ & $\begin{array}{l}\text { Örneklem Sayısı } \\
\text { ve Özellikleri }\end{array}$ & Araştırma Amacı & Temel Bulgular \\
\hline $\begin{array}{l}\text { Uzun, C., Adalı, } \\
\text { M.K., Koten, } \\
\text { M., Karasali- } \\
\text { hoğlu, A.R., } \\
\text { Adalı, I., } \\
\text { Devren, M. } \\
\text { (2001) } \\
\end{array}$ & $\begin{array}{l}\text { Sportif SCUBA } \\
\text { dalıcılı̆ı̆n } \\
\text {, işitme üzerine } \\
\text { etkisi: Araştır- } \\
\text { mada } \\
\text { karşılaşılan so- } \\
\text { runlar ve bilg- } \\
\text { ilendirme öner- } \\
\text { ileri }\end{array}$ & $\begin{array}{l}\text { Katılımcıları bir } \\
\text { yıl süreyle takibe } \\
\text { - alıp yapılan } \\
\text { işitme testleri }\end{array}$ & $\begin{array}{l}\text { Trakya Üniversi- } \\
\text { tesi Tip } \\
\text { Fakültesince tespit } \\
\text { edilen, başlangıçta } \\
\text { 53, bir yıl sonunda } \\
11 \text { dalgıç }\end{array}$ & $\begin{array}{l}\text { Bir yıllık süreyle } \\
\text { aynı kişilere } \\
\text { yapılan testler so- } \\
\text { nucu aletli dalışın } \\
\text { işitme kaybına yol } \\
\text { açıp açmadığının } \\
\text { tespiti }\end{array}$ & $\begin{array}{l}\text { Aletli dalışın işitme üzerine } \\
\text { olumsuz etkisi olmadığını } \\
\text { göstermesine rağmen, konu } \\
\text { üzerinde daha çok sayıda } \\
\text { örnek ve daha düzenli tak- } \\
\text { ipli çalışmalara gerek vardır }\end{array}$ \\
\hline $\begin{array}{l}\text { Uzun, C., Taş, } \\
\text { A., Yağız, R., } \\
\text { Çiçek, F., İnan, } \\
\text { N. } \\
(2001)\end{array}$ & $\begin{array}{l}\text { Sportif SCUBA } \\
\text { dalıclarında } \\
\text { KBB sorunları, } \\
\text { tedavileri ve } \\
\text { korunma yol- } \\
\text { lar1 }\end{array}$ & $\begin{array}{l}\text { Katılımcllar } \\
\text { üzerinde yapılan } \\
\text { işitme testleri }\end{array}$ & $\begin{array}{l}\text { Trakya Üniversi- } \\
\text { tesi Tıp } \\
\text { Fakültesince tespit } \\
\text { edilen } 37 \text { dalgıç }\end{array}$ & $\begin{array}{l}\text { Yapılan testler so- } \\
\text { nucu aletli dalışın } \\
\text { işitme kaybına yol } \\
\text { açıp açmadığının } \\
\text { tespiti }\end{array}$ & $\begin{array}{l}\text { Dikkatli muayene ile uygun } \\
\text { eğitim ve tedbirler } \\
\text { alındığında aletli dalışın } \\
\text { oldukça güvenli bir spor } \\
\text { olduğu sonucuna varıldı }\end{array}$ \\
\hline $\begin{array}{l}\text { Bilge, A.D., } \\
\text { Akçakaya, A.A., } \\
\text { Yaylalı, S.A., Er } \\
\text { bil, H.H. } \\
(2008)\end{array}$ & $\begin{array}{l}\text { Tüplü Dalış İle } \\
\text { İlişlkili Oküler } \\
\text { Patolojiler, Bir } \\
\text {.,Subkonjonk- } \\
\text {-tival } \\
\text { Kanama Ol- } \\
\text { gusu }\end{array}$ & $\begin{array}{l}\text { Katılımcıda aletli } \\
\text { dalış sonrası be- } \\
\text { liren göz ra- } \\
\text { hatsızlığı } \\
\text { gözlemleme }\end{array}$ & $\begin{array}{l}\text { İstanbul Göztepe } \\
\text { Eğitim ve } \\
\text { Araştırma Has- } \\
\text { tanesi Göz Has- } \\
\text { talıkları Klinigi } \\
\text { asistanı } 1 \text { dalgıç }\end{array}$ & $\begin{array}{l}\text { Aletli dalış sonrası } \\
\text { gözlerde oluşan } \\
\text { hemorajinin } \\
\text { (kızarıklık) sebebi, } \\
\text { bu durumun kalıcı } \\
\text { olup olmadığı }\end{array}$ & $\begin{array}{l}\text { Aletli dalış kontakt lens } \\
\text { kullanan, maskenin } \\
\text { buğulanmasını önleyici } \\
\text { kimyasal kullanan, dalış } \\
\text { öncesi herhangi bir göz } \\
\text { ameliyatı geçirmiş kimseler } \\
\text { gibi bazı durumlarda basınç } \\
\text { kaynaklı gözlerde bazı ra- } \\
\text { hatsızlıklara sebebiyet vere- } \\
\text { bilir }\end{array}$ \\
\hline $\begin{array}{l}\text { Kahraman, B.B., } \\
\text { Aşiret, G.D., } \\
\text { Devrez, N., } \\
\text { Özdemir, L. Ak- } \\
\text { demir, N. } \\
(2012) \\
\end{array}$ & $\begin{array}{l}\text { Dalış Sporu ve } \\
\text {., Dalışlarda } \\
\text { Yaşanan Sağllk } \\
\text { Sorunlarının } \\
\text {-Önlenmesinde } \\
\text { Hemşirenin } \\
\text { Rolü } \\
\end{array}$ & & Derleme & $\begin{array}{l}\text { Hemşirelerin aletli } \\
\text { dalış sonrası } \\
\text { oluşabilecek tıbbi } \\
\text { problemlerin } \\
\text { önlenmesinde } \\
\text { etkisi olup olma- } \\
\text { dığı }\end{array}$ & $\begin{array}{l}\text { Hemşirelerin dalış spo- } \\
\text { runun sağlık üzerine etkisi, } \\
\text { kronik hastalıklarla ilişkisi } \\
\text { ve ilk yardım konularında } \\
\text { eğitimler vermesi ve düzenli } \\
\text { aralıklarla sağlık kontrol- } \\
\text { lerinin tekrarlanması ile } \\
\text { dalış güvenliğinin sağlana- } \\
\text { cağı düşünülmektedir } \\
\end{array}$ \\
\hline $\begin{array}{l}\text { Özyiğit, T., Egi, } \\
\text { S.M. } \\
(2018)\end{array}$ & $\begin{array}{l}\text { Dalış Bilgisa- } \\
\text { yarlarının Er- } \\
\text { gonomik Per- } \\
\text { formansları } \\
\text { Değer- } \\
\text { lendirilmesi }\end{array}$ & $\begin{array}{l}\text { Çok ölçütlü karar } \\
\text { verme yöntemi } \\
\text { kullanılarak } \\
\text { düzenlenen anket }\end{array}$ & $\begin{array}{l}\text { Farklı ülkelerden } 4 \\
\text { kadın, } 16 \text { erkek } \\
\text { t dalgıç }\end{array}$ & $\begin{array}{l}\text { Kullanıcı dostu ve } \\
\text { etkin bir dalış bilgi- } \\
\text { sayarının güvenli } \\
\text { ve konforlu bir } \\
\text { dalış üzerine etkisi }\end{array}$ & $\begin{array}{l}\text { Dalış bilgisayarlarının } \\
\text { birçok değişik özelliği } \\
\text { olmakla beraber, kullanıcılar } \\
\text { ergonomik yetersizliklerden } \\
\text { dolayı bu özellikleri etkin } \\
\text { olarak kullanamadıkları du- } \\
\text { - rumda yeterli verim alına- } \\
\text { mamakta, hatta dalış ka- } \\
\text { zalarına ve acil durumlara } \\
\text { davetiye çıarılmaktadır }\end{array}$ \\
\hline
\end{tabular}




\begin{tabular}{|c|c|c|c|c|c|}
\hline $\begin{array}{l}\text { Sevinç, F., Özel, } \\
\text { Ç.H. } \\
\text { (2018) }\end{array}$ & $\begin{array}{l}\text { Boş Zaman Ak } \\
\text { tivitesi Olarak } \\
\text { Dalış ve Yaşam } \\
\text { Doyumu İle } \\
\text { İlişkisi } \\
\end{array}$ & $\begin{array}{l}\text { Yarı } \\
\text { yapılandırılmış } \\
\text { derinlemesine } \\
\text { görüşme }\end{array}$ & $\begin{array}{l}\text { Çanakkale ve } \\
\text { Eskişehir'deki } \\
\text { dalış kulüpleri } \\
\text { üyesi } 28 \text { dalgıç }\end{array}$ & $\begin{array}{l}\text { Dalış yapan birey- } \\
\text { lerin boş zaman ak- } \\
\text { tivitesi olarak dalışı } \\
\text { nasıl gördükleri ve } \\
\text { dalış aktivitesinin } \\
\text { yaşam } \\
\text { doyumlarıyla bir } \\
\text { ilişkisinin olup } \\
\text { olmadığı }\end{array}$ & $\begin{array}{l}\text {-Görüşmeler neticesinde, } \\
\text { 1 dalmanın bireylerin } \\
\text { hayatında önemli bir yere } \\
\text { sahip olduğu, keşfetmeye, } \\
\text { sosyalleşmeye, kendini } \\
\text { dinlemeye ve ruhen yenilen- } \\
\text { meye katkısının olduğu be- } \\
\text { lirlenmiştir }\end{array}$ \\
\hline $\begin{array}{l}\text { Egi, S.M., Al- } \\
\text { tepe, C., Pieri, } \\
\text { M., Sinoplu, } \\
\text { D.R., Özyiğit, } \\
\text { T., Pierleoni, P., } \\
\text { Marroni, A. } \\
\text { (2018) } \\
\end{array}$ & $\begin{array}{l}\text { Design and Im } \\
\text { plementation } \\
\text { of an Underwa } \\
\text { ter } \\
\text { Telemetric Glu } \\
\text { cose Monitor- } \\
\text { ing System for } \\
\text { Scuba Divers } \\
\end{array}$ & $\begin{array}{l}\text { Dalgıçların } \\
\text { - vücutlarına yer- } \\
\text { leştirilen su } \\
\text { 1-geçirmez, ka- } \\
\text { blosuz sensör ve } \\
\text {-bu verileri yine } \\
\text { su geçirmez mo- } \\
\text { dem kanalıyla } \\
\text { yüzeye aktarma } \\
\end{array}$ & $\begin{array}{l}\text { Diyabet hastası } 51 \\
\text { yaşında } 1 \text { erkek ve } \\
33 \text { yaşında bir } \\
\text { kadın dalgıç }\end{array}$ & $\begin{array}{l}\text { Diyabet has- } \\
\text { talığının aletli dalış } \\
\text { yapanlarda sual- } \\
\text { tında bayılma gibi } \\
\text { risklere sebep olup } \\
\text { olmadığının tespiti }\end{array}$ & $\begin{array}{l}\text { Aletli dalışın diyabet has- } \\
\text { taları için ilave bir risk } \\
\text { taşıyıp taşımadığı ko- } \\
\text { nusunda karara varabilmek } \\
\text { için çalışma sonuçlarından } \\
\text { yeterince bilgi edinilemedi }\end{array}$ \\
\hline $\begin{array}{l} \\
\text { Memişoğlu, M., } \\
\text { Özyiğit, T., } \\
\text { Şatır, S., Egi, } \\
\text { S.M. } \\
(2019) \\
\end{array}$ & $\begin{array}{l}\text { Development } \\
\text { of a Wireless } \\
\text { Pressure Sen- } \\
\text { sor Module to } \\
\text { Convert the } \\
\text { Mobile Phones } \\
\text { into Dive Com- } \\
\text { puters }\end{array}$ & Derleme & Derleme & $\begin{array}{l}\text { Sugeçirmez bir } \\
\text { taşıma düzeneği ve } \\
\text { harici bir elektronik } \\
\text { düzenleme sistemi } \\
\text { kullanarak cep tele- } \\
\text { fonlarını dalış bilgi- } \\
\text { sayarına çevirmek }\end{array}$ & $\begin{array}{l}\text { Geliştirilen sistem mevcut } \\
\text { dalış bilgisayarları ile test } \\
\text { kedildi ve gerek veri akışı, } \\
\text { gerekse dalgıca sunduğu } \\
\text {-bilgilerde herhangi bir } \\
\text {-aksaklık, yanlışlık } \\
\text { saptanmadı }\end{array}$ \\
\hline $\begin{array}{l}\text { Çulha, O., } \\
\text { Gönül, E. } \\
(2019)\end{array}$ & $\begin{array}{l}\text { Su Altı Dalış } \\
\text { Motivasyonu: } \\
\text { Demografik ve } \\
\text { Deneyimsel } \\
\text { Özellikler } \\
\text { Bakımından } \\
\text { Değer- } \\
\text { lendirilmesi }\end{array}$ & $\begin{array}{l}\text { Türkiye'deki } \\
\text { dalı̧̧ merkezle- } \\
\text { rinin sosya } \\
\text { medya hesaplar- } \\
\text { Indan üyelerinin } \\
\text { çevrimiçi } \\
\text { katılımları }\end{array}$ & $\begin{array}{l}\text { Araştırmaya } \\
\text { katılan } 261 \text { dalgıç }\end{array}$ & $\begin{array}{l}\text { Çalışmanın temel } \\
\text { amacı sualtı dalış } \\
\text { yapanların moti- } \\
\text { vasyonlarını belir- } \\
\text { lemektir. Daha } \\
\text { özelde dalış yapan- } \\
\text { ları dalış yapmaya } \\
\text { iten ve çeken fak- } \\
\text { törlerin } \\
\text { neler olduğunu be- } \\
\text { lirlemektir }\end{array}$ & $\begin{array}{l}\text { Katılımcıları dalış yapmaya } \\
\text { iten en önemli motivasy- } \\
\text { onun dalış deneyimi, çeken } \\
\text { en önemli motivasyonun } \\
\text { temel dalış özellikleri } \\
\text { olduğu tespit edilmiştir. } \\
\text { - Ayrıca dalış yapmaya çeken } \\
\text { hiçbir motivasyon faktörü } \\
\text { demografik ve deneyimsel } \\
\text { özelliklere göre anlamlı bir } \\
\text { farklılık } \\
\text { göstermemiştir }\end{array}$ \\
\hline $\begin{array}{l}\text { Doğru, H., } \\
\text { Çelik, B., } \\
\text { Yilmaz, B.S. } \\
(2019)\end{array}$ & $\begin{array}{l}\text { Dalış Turizmi } \\
\text { Emniyeti: Risk } \\
\text { Faktörleri ve } \\
\text { Çözüm Öner- } \\
\text { ileri }\end{array}$ & $\begin{array}{l}\text { Yarı } \\
\text { yapilandırılmış } \\
\text { derinlemesine } \\
\text { görüşme }\end{array}$ & $\begin{array}{l}\text { İzmir'de faaliyet } \\
\text { gösteren dalış } \\
\text { merkezlerinde } \\
\text { çalışan } 10 \text { dalış } \\
\text { eğitmeni }\end{array}$ & $\begin{array}{l}\text { Dalgıçların karşı- } \\
\text { laştıları kaza ve } \\
\text { yaralanma den- } \\
\text { eyimleri, bunları } \\
\text { oluşturan risk fak- } \\
\text { törleri ve bunları } \\
\text { önlemeye yönelik } \\
\text { alınan tedbirleri } \\
\text { ortaya koymak }\end{array}$ & $\begin{array}{l}\text { Dalışla ilgili en sık } \\
\text { karşılaşılan kaza, yaralanma } \\
\text { ve hastalıklar tüp düşmesi, } \\
\text { kayarak düşme, kulak zarı } \\
\text { zedelenmesi, kesik ve küçük } \\
\text { çizikler, sualtında } \\
\text { oluşabilecek kramp ve } \\
\text { spazmlardır } \\
\text { Katılımcılar en çok fotoğraf } \\
\text { çekmek, huzura kavuşmak, } \\
\text { su altındaki bitkileri ve } \\
\text { hayvanları tanımak, farklı }\end{array}$ \\
\hline $\begin{array}{l}\text { Dağlıoğlu, T., } \\
\text { Sürme, M. } \\
\text { (2019) }\end{array}$ & $\begin{array}{l}\text { Turizmi Tercih } \\
\text { Nedenlerini Be } \\
\text { lirlemeye } \\
\text { Yönelik Bir } \\
\text { Araştırma }\end{array}$ & $\begin{array}{l}\text {-Kolayda } \\
\text { örnekleme yönt- } \\
\text { emi ile düzen- } \\
\text { lenen anket }\end{array}$ & $\begin{array}{l}\text { Hatay Samandağı } \\
\text { ilçesi Uzunkaya } \\
\text { Bölgesi dalışı son- } \\
\text { rasında anketlere } \\
\text { katılan } 11 \text { dalgıç }\end{array}$ & $\begin{array}{l}\text { Çalışmaya katılan- } \\
\text { ların su altı dalış } \\
\text { turizmi tercih } \\
\text { nedenleri ortaya } \\
\text { koymak }\end{array}$ & $\begin{array}{l}\text { dünyaları keşfetmek, iş } \\
\text { stresinden uzaklaşmak gibi } \\
\text { nedenlerden dolayı sualtı } \\
\text { dalış turizmini tercih ettikle- } \\
\text { rini belirtmişlerdir }\end{array}$ \\
\hline
\end{tabular}




\begin{tabular}{|c|c|c|c|c|c|}
\hline $\begin{array}{l}\text { Körpınar, Ş. } \\
\text { (2019) }\end{array}$ & $\begin{array}{l}\text { Patent Fora- } \\
\text { men Ovale ve } \\
\text { Dalış }\end{array}$ & Derleme & Derleme & $\begin{array}{l}\text { PFO'nun dalış } \\
\text { tıbbındaki yeri ile } \\
\text { ilgili } \\
\text { guncel veriler } \\
\text { tartışılmaktadır }\end{array}$ & $\begin{array}{l}\text { Dekomprasyon hastalığı } \\
\text { (DH) gelişiminde en onemli } \\
\text { faktörün dalış profili } \\
\text { olduğu, en başarılı kapatma } \\
\text { işleminin dahi agresif bir } \\
\text { dalış profili varlığında DH } \\
\text { oluşumunu engelleyemey- } \\
\text { eceği riskin yalnızca nor- } \\
\text { male döndüğü ve asla sıfır- } \\
\text { lanamayacağı }\end{array}$ \\
\hline $\begin{array}{l}\text { Gülşahin, A., } \\
\text { Cerim, H., } \\
\text { Soykan, O. } \\
(2020)\end{array}$ & $\begin{array}{l}\text { Su Ürünleri } \\
\text { Mühendis- } \\
\text { liği'nde } \\
\text { Donanımlı } \\
\text { Dalışın İş } \\
\text { Sağlığı ve } \\
\text { Güvenliği } \\
\text { Açısından } \\
\text { Değer- } \\
\text { lendirilmesi }\end{array}$ & Yüz yüze anket & $\begin{array}{l}\text { Ege Bölgesi'nde } \\
\text { aletli dalış } \\
\text { gerçekleştiren } 123 \\
\text { adet su ürünleri } \\
\text { mühendisi }\end{array}$ & $\begin{array}{l}\text { Bu çalışmada Tü- } \\
\text { rkiye'de aletli dalış } \\
\text { yapan su ürünleri } \\
\text { mühendislerinin iş } \\
\text { sağlığı ve güvenliği } \\
\text { konusundaki tu- } \\
\text { tum ve dav- } \\
\text { ranışları, güvenlik } \\
\text { farkındalıkları, iş } \\
\text { kazası ve meslek } \\
\text { hastalıkları den- } \\
\text { eyimlerinin belir- } \\
\text { lenmesi } \\
\text { amaçlanmıştır. }\end{array}$ & $\begin{array}{l}\text { Çalışma sonuçlarına göre, } \\
\text { i katılımcıların büyük } \\
\text { kısmının yeterli dalış belge- } \\
\text { lerine sahip olmadan } \\
\text { çalıştıkları, gereksiz yere } \\
\text { risk almak zorunda } \\
\text { kaldıkları, malzeme ve ekip- } \\
\text { manların yetersiz olduğu, } \\
\text { bütün bunlara bağlı iş ka- } \\
\text { zaları oluştuğu tespit } \\
\text { edilmiştir }\end{array}$ \\
\hline $\begin{array}{l}\text { Höbek, A., } \\
\text { Toklu, A.S., Bal- } \\
\text { kis-Ozdelice, } \\
\text { N., Alıçlı, B.N. } \\
(2020)\end{array}$ & $\begin{array}{l}\text { Ölümcül Dalış } \\
\text { Kazalarında } \\
\text { Boğulma Der- } \\
\text { inliğinin Belir- } \\
\text { lenmesinde } \\
\text {-Planktonik } \\
\text { Organizmalar } \\
\text { Yardımcı } \\
\text { Olabilir mi? }\end{array}$ & IYçüz yüze ve & $\begin{array}{l}\text { Wistar Albino türü } \\
8 \text { fare } \\
\text { Türkiye'deki Su } \\
\text { Ürünleri Fakültel- } \\
\text { eri'ndeki } 65 \text { akade- } \\
\text { misyen ve } \\
\text { lisansüstü öğren- } \\
\text { cisi }\end{array}$ & $\begin{array}{l}\text { Bu çalışmada, } \\
\text { ölümcül dalış ka- } \\
\text { zalarında, boğulma } \\
\text { derinliğinin tespit- } \\
\text { inde planktonik or- } \\
\text { ganizmaların } \\
\text { kullanılıp kullanıla- } \\
\text { i mayacağının tespiti } \\
\text { amaçlanmıştır } \\
\text { Türk üniver- } \\
\text { sitelerinde dalışı } \\
\text { bir araç veya amaç } \\
\text { olarak kullanan } \\
\text { başlıca } \\
\text { disiplinlerden su } \\
\text { ürünleri ve deniz } \\
\text { - bilimlerinde } \\
\text { gerçekleştirilen } \\
\text { çalışmaların nicel } \\
\text { olarak incelenmesi }\end{array}$ & $\begin{array}{l}\text { Ülkemizde birçok üniversite } \\
\text { ve bilimsel kurum denizel } \\
\text { yaşamı ve sahip olduğu } \\
\text { değerleri insanlara anlatmak } \\
\text { için çaba sarf etmektedir. } \\
\text { Ulusal bir bilimsel dalış } \\
\text { komitesinin oluşturulması } \\
\text { bu çabayı daha görünür } \\
\text { kılabilecektir }\end{array}$ \\
\hline
\end{tabular}

Tablo 4 incelendiğinde 20 yıllık süreçte aletli dalışla ilgili en çok yayınlanan makale sayısına 5 makale ile 2019 yılında ulaşıldığı, bu rakamı 3'er makale ile 2018 ve 2020 yıllarının takip ettiği, 2001 yılında konu hakkında 2 makale yayınlandığı, en az makalelerin ise 1'er makale ile 2008 ve 2012 yıllarında yayınlandığı görülmektedir. Son yıllarda aletli dalış konusunda yapılan araştırmalara ilgi nispeten artmış görünse de son 2 yılda yayınlanan toplam makale sayısının 8 olduğu dikkate alındığında bu rakamın 
yetersiz kaldığı ortaya çıkmaktadır. Ayrıca kayda değer bir diğer sonuç 2001-2008 arasındaki 7 yıl ve 2012-2018 arasındaki 6 yıl hiç makale yayınlanmamış olmasıdır.

Makalelerin yayınlandıkları bilim alanları dikkate alındığında aynı sene yayınlanan ve neredeyse birbirinin benzeri olan 2 makale de dahil olmak üzere en fazla yayının 7 makale ile Tip, ardından 3 makale ile Sosyal Bilimler konularında yapıldığı; geri kalanların da ikişer makaleyle Bilgisayar Mühendisliği ile İş Sağlı̆̆ı ve Güvenliği, 1 makale ile de Su Ürünleri Mühendisliği konularına ait oldukları tespit edilmiştir. Aletli dalışın turizm açısından önemine daha önce değinildiği için bu konu tekrar edilmeyecektir. Durum böyleyken konu hakkında Sosyal Bilimler alanında yapılmış olan çalışmaların azlığı düşündürücüdür.

Araştırmalarda kullanılan veri toplama yöntemleri incelendiğinde 5 makalenin nicel, 4 makalenin tıbbi ve laboratuvar testleri, 3 makalenin derleme, 2 makalenin nitel ve 1 makalenin de "araştırmacının kendisini gözlemleme" yöntemleriyle hazırlandı̆̆ 1 görülmektedir. Nitel çalışmaların azlığı yanında "kendini gözlemleme" gibi bilimselliği tartı̧̧malı bir yöntemin de yapılan çalışmalar arasında yer alması kanımızca not edilmeye değer olarak görülmüştür.

İlgili tablonun takip eden sütununda yer alan “örneklem sayısı ve özellikleri" bölümü de kendi içerisinde farklılıklar göstermektedir. Derleme çalışmalar bir tarafa bırakıldığında, 1 çalışmanın aletli dalışın birden fazla dalıştaki etkisini ölçmek amacıyla bir yıllık süreçte 53 katılımcıyla başladığı katılımcı sayısı bir yılın sonunda 11'e düşmüş, bu da sonuçların geçerliliği konusunu tartışmalı hale getirmiştir. Bu alandaki bir diğer dikkat çeken husus, bazı nicel çalışmaların, yine araştırma bulgularını "güvenilirlik" yönünden etkileyecek şekilde 20, hatta 11 kişi gibi çok düşük miktarlarda katılımcılardan elde edilen verilerle hazırlanmış olmalarıdır.

Yayınlanan makaleler "araştırma amaçlarına" göre incelendiğinde aletli dalışın kulaklarda olan etkisi, dalışta kullanılan maskenin gözlere yaptığı baskı, diyabet hastalarının aletli dalıştan nasıl etkilendikleri gibi Tıbbi çalışmaların belirli bir alanına yoğunlaşmış ve bulgularının sosyal bilimlere hiç bir katkısı olmayan yayınlar olduğu gibi, hemşirelerin olası dalış kazalarını önlemedeki rolleri şeklinde gerek metodolojik, gerekse veri toplama ve analiz yönünden bulguları okuyanların zihinlerinde soru işaretleri uyandırabilecek çalışmalar bulunmaktadır. Mühendislik 
konularında da yazılan makaleler bu eleştireleri haklı çıkaracak örnekleri barındırmakta, aynı şekilde sosyal bilimler alanına neredeyse hiç katkıda bulunmamaktadırlar, dalış bilgisayarlarının ergonomik özelliklerini inceleyen veya cep telefonlarının dalış bilgisayarına dönüştürülme potansiyelini araştıran yayınlarda olduğu gibi. Yine mühendislik konusuna giren ve aletli dalışta iş sağlığı ve iş güvenliği konularını araştıran bir adet makale her ne kadar sinırlı verilerle ve belirli bir bölge incelenerek hazırlanmış olsa da, en azından bulgularından dalışla ilgilenen herkesin az veya çok istifade etmesi açısından daha işlevsel bir görüntü sunmaktadır. Sosyal bilimler konusuna giren makaleler ise toplam yayınların içerisinde adet olarak çok az bulunmanın yanında kendi içlerinde 'yaşam doyumu' veya 'motivasyon' gibi çok genel konuları araştırmaları ve araştırma bulgularının toplanan sınırlı veriler ve analiz yöntemleriyle genelleme yapılmasının zorluğu gibi değişik kısıtlamalar içermektedirler. Tabloda yer alan son sütunun incelenmesi ile araştırmamıza konu olan çalışmaların temel bulguları ifade edilmektedir. Tıp alanında yazılan makalelerin bulguları incelendiğinde, gerekli emniyet tedbirleri alınıp kurallar dahilinde aletli dalış yapıldığı taktirde dalışın incelenen konuya (örn. kulak zarı) zararı olmadığı veya kesin bir sonuca ulaşmak için elde yeterli veri bulunmadığı tespit edilmiştir. Yine aynı bilim alanında yapılan diğer çalışmalardan da sağlık personelinin (örn. hemşireler) dalgıçları uyarması ve bilgilendirmesi ile dalış kazalarının önlenebileceği, dekomprasyon hastalığının (vurgun) en temel sebeplerinin dalış profilleri, yani dalış limitlerine uymama veya limitleri gereksiz yere zorlama, tek başına dalış yapmanın kaza ve yaralanma riskini arttırdığı şeklinde muhtemelen her tecrübeli dalgıcın tahmin edebileceği, belki de araştırma yapmaya gerek bile olmayan sonuçlar elde edilmiştir. Mühendislik alanında yapılan bazı çalışmaların bulguları da Tıp konusunda yapılan bazı çalışmalara benzer şekilde sınırlı kalmış, “dalış bilgisayarlarının ergonomik dizaynları kullanımı kolaylaştırmaktadır" gibi sonuçlarla aletli dalış yapanların sınırsız bir bütçesi olup, kullanımı kolay bilgisayarları tercih edecekleri gibi tartışmalı yorumlara yol açabilecek ifadelerin kullanılmalarına zemin oluşturmuşlardır. Yine mühendislik alanına giren iş sağlığı ve iş güvenliği konusunda yapılan bir çalışma bu konuda incelenen dalış bölgesindeki mevzuata aykırı veya eksik uygulamarı tespit etmesi açısından kısmen önem gösterdiği söylenebilir. Son olarak, sosyal bilimler alanında yazılan 
makalelerin bulgularına yorum yapmak gerekirse, içlerinde aletli dalışın bireylerin sosyalleşmesine katkıda bulunduğu, dalış bölgesi tercihinde temel nedenlerden birisinin bölgenin özelliği olduğu, dalış esnasında fotoğraf çekmekten keyif alındığı gibi yine muhtemelen araştırma yapmadan da aynı sonuçlara ulaşılabilecek makaleler bulunduğu gözlenmiştir. Nitel yöntemler kullanılarak yapılan bir çalışma ise dalış esnasında karşılaşılan çoğu yaralanmaların teknede kayıp düşme veya ayağa tüp, ağırlık düşme gibi sebeplerden kaynaklandığı gibi faydalı olabilecek bazı tespitlerde bulunmuş olsa da, önceki eleştirilere benzer şekilde, bu sonuç da sanki malumun ilanı gibi durmakta, ayrıca çalışma belirli bir dalış bölgesindeki farklı tecrübe ve yaş grubundaki on dalış eğitmeni ile yapılan görüşmelere dayandığı için bulgulardan genelleme yapılması güçleşmektedir.

\section{Tartışma ve Sonuç}

Aletli dalış dünya genelinde pek çok insanı cezbeden, bir ülkeden başka bir ülkeye bu amaçla seyahat edilmesine sebep olan, bütün bu süreçte ziyaret edilen ülkelere turizm bakımından katkı sağlayan bir aktivitedir. Dünya genelinde Avustralya, Mısır, Endonezya gibi dalış turizmi yönünden tanınmış ve turistlerin yoğun bir şekilde ziyaretine uğrayan ülkeler ve tanınmış Kızıldeniz, Büyük Mercan Kayalıkları gibi aletli dalış bölgeleri bulunmaktadır. Dalışla ilgili planlamalar çeşitli sualtı canlıları veya batık gibi özel konularda olabildiği gibi tekne turları şeklinde dalış yapmayanların katılabileceği günlük hatta gece konaklamalı şekilde de olabilmektedir. Dünya çapında tanınmış veya çok fazla ziyaretçi çeken dalış bölgeleri bulunmasa da ülkemizde de farklı zevklere hitap eden pek çok dalış noktası bulunmakta, üç tarafı denizlerle çevrili olmasının avantajı her bölgenin bir diğerine göre farklı bir dalış tecrübesi sunması gibi pozitif bir şekilde aletli dalış severlere yansımaktadır.

Konu hakkında ülkemizde yapılan akademik çalışmalar incelendiğinde ise yapılan çalışmaların çok yetersiz, sayıca az ve pek çoğunun sosyal bilimler alanında değil de fen bilimlerinde ve çoğu zaman da yapılan çok özel bir çalışmanın parçası olarak yapıldıkları gözlenmektedir. Yapılan bazı çalışmaların küçük gruplar üzerinde ve kısıtlı verilerle, hatta "kişisel gözlem" gibi akademik değeri tartışılabilecek 
metodlar kullanarak sonuçlandığı dikkate alındığında aletli dalış konusunda çok daha fazla, farklı amaçlar için farklı metodlar kullanarak, özellikle de sosyal bilimler ve turizm alanında çalışmaların yapılmasına ihtiyaç olduğu açıktır. Bu çalışmadan çıkan bir diğer sonuç ise literatürde dalışla ilgili standart bir terimin bulunmamasıdır. Kimi çalışmalar bizim de tercih ettiğimiz "aletli dalış" tanımlamasını kullanmış, "tüplü dalış", İngilizce'de aynen kullanıldığı gibi "SCUBA" veya "donanımlı dalış" gibi farklı versiyonlar kullanılmış, hatta bir kaç çalışma aynı metin içersinde birden fazla tanımlamayı tercih etmiştir. Ayrıca, sadece kullanılan araştırma yöntemi türü bile dikkate alındığında daha önce yapılan çalışmalarda nitel araştırmaların azlığı bariz bir şekilde ortaya çıkmakta, "karma araştırma yöntemleri" metodunun ise hiç kullanılmadı̆̆ 1 görülmektedir.

Bu çalışma konu hakkında daha önce yapılan çalışmaları kronolojik olarak bir araya toplayıp araştırmacılara sunma kolaylığı sağlamasının yanında bahsedilen eksik ve yetersiz araştırma konu ve yöntemlerinin tespit edilmesi sayesinde gelecek araştırmalara yol göstermekte, bu sayede ilerde daha faydalı ve nitelikli çalışmaların hazırlanmasına bir nebze de olsa katkıda bulunması beklenmektedir. 


\title{
EXTENDED ABSTRACT
}

\section{Scuba Diving Literature Review in Turkey for the Past 20 Years \\ *}

\author{
Alper Bozkurt \\ Adana Alparslan Türkeş University
}

Throughout the history, human beings always showed interest towards underwater world one way or another. Either for sports diving or commercial diving, we tried different methods to stay under sea and using some sort equipment meant we could stay longer, do certain tasks easier, hence the benefits. Skin diving (without any aiding equipment) was always practiced throughout the history, diving for extracting sponges and pearls are good examples to this. It is, however, not until the introduction of the scuba equipment, human beings started to scratch exploring the seabed. French oceanographer and explorer Jacques-Yves Cousteau and his team contributed greatly to this quest by designing "aqualung", a system allows the diver without the need of bulky and difficult use of equipment, a system is still used and even preferred by some today.

Using the capital letters of each, the word Scuba was derived from Self Contained Breathing Apparatus. It is estimated that in 2021, North America alone accommodates 2.6 million certified divers (holding a diving qualification from an organisation). The number is about 3.5 million in Europe and more than 6 million all around the world (Scubanomics, 2021). When it comes to the organisations that teach scuba diving and certify divers, North America rather leads the world, followed by Europe. There are also many known, rather famous scuba diving sights or spots in the world. Based on the participants' ratings (the list may vary), top ten sites are located in Australia, Malaysia, Indonesia and Thailand. On this matter, Australia tops the list with the amount of famous diving sites, followed by Indonesia, Thailand and Malaysia (divezone.net 2021). In Turkey the city with the most famous (highest rated by the scuba participants) is Mugla, followed by Antalya, Canakkale and Istanbul (Gezimanya, 2021). When compared with the amount of Turkish Federation (TSSF) registered scuba diving or dive centres, the city with the most dive centres is Antalya, followed by Istanbul, Izmir, Mugla, Ankara, Canakkale, Mersin, Kocaeli, 
Balikesir, Bursa, Aydin, Sakarya, Edirne, Eskisehir, Isparta, Manisa, Samsun, Tekirdag, Trabzon and Van (TSSF, 2021).

This paper examines scholarly written and published articles in Turkey for the past 20 years. While doing it, Turkish government owned search engine, "TR Dizin" was used. The reason for this is to standardise the article search and leave out the journals that are not registered at TR Dizin. Findings indicated that despite having reasonably well and reputable scuba diving sights in Turkey, none of them made it through top ten list in the world. The study also found that medical studies on the subject were the highest in numbers among, followed by engineering. Social studies, especially the ones on any subject related to tourism were surprisingly low. In terms of recently published ones, there was increase of recently published article numbers, however, still lower than expected. Another interesting finding on this matter was, between certain years there were no published articles as if the topic went completely off the academia's radar. There were question marks on the quality of some articles that were published. On top of being very specific such as a certain sub discipline in medicine or engineering, a number of articles employed very questionable research techniques like "one's personal observation on oneself" or making assumption based on a very small amount of questionnaire data. Although a couple of recent articles employed more solid data collection methods such as face-to-face interviews, assumptions stated on the "findings" section of these articles still raised a number of question marks, simply casting doubts on the integrity of the studies.

Based on all these findings, it is fair to state that scuba diving is an activity that attracts millions of people throughout the world. People travel great distances and spend reasonable amount of time and money to pursue their hobby. Despite having great potential in terms of scuba diving sites with picturesque views and one-off experiences, Turkey lacks far behind countries like Australia and Indonesia to attract divers. There could be a number of reasons for this, perhaps one of them is not enough advertisement, investing less on the infrastructure and not regulating the industry as well, leaving the business to "profit only" companies and individuals. When it comes to academia, the situation is not different from the practitioners, or even worse. There are only a few articles written on scuba diving related matters, and only a handful of them under social sciences 
category, let alone in tourism. This rather pessimistic picture casts doubts on the future of scuba diving in Turkey, but as always, one always keeps hope and tries to improve the situation, even it meant working alone and trying harder, hence the direction for the future studies.

\section{Kaynakça / References}

Sofular, H.Ş. (1992). Dalgıç. İstanbul: Ema Matbaacilık.

Uzun, C., Adalı, M.K., Koten, M., Karasalihoğlu, A.R., Adalı, İ. ve Devren, M. (2001). Sportif SCUBA dalıcilığın işitme üzerine etkisi: Araştırmada karşılaşılan sorunlar ve bilgilendirme önerileri. Kulak Burun Boğaz İhtisas Dergisi, 8(2), 124-129.

Uzun, C., Taş, A., Yağız, R., Çiçek, F. ve İnan, N. (2001). Sportif SCUBA Dal1cllarında KBB sorunları, tedavileri ve korunma yolları. Kulak Burun Boğaz İhtisas Dergisi, 8(4), 281-288.

Bilge, A.D., Akçakaya, A.A., Yaylalı, S.A. ve Erbil, H.H. (2008). Tüplü dalış ile ilişkili oküler patolojiler, bir subkonjonktival kanama olgusu. Türk Oftalmoloji Dergisi, 38, 446-448.

Matsen, B. ve Cousteau, J. (2009). The sea king. New-York: Pantheon Books.

Kahraman, B.B., Aşiret, G.D., Devrez, N., Özdemir, L. ve Akdemir, N. (2012). Dalış sporu ve dalışlarda yaşanan sağlık sorunlarının önlenmesinde hemşirenin rolü. Sağllk Bilimleri Fakültesi Hemşirelik Dergisi, 73-81.

Egi, S.M., Altepe, C., Pieri, M., Sinoplu, D.R., Özyiğit, T., Pierleoni, P. ve Marroni, A. (2018). Design and implementation of an underwater telemetric glucose monitoring system for scuba divers. Hittite Journal of Science and Engineering, 5(2), 141-146.

Özyiğit, T. ve Egi, S.M. (2018). Dalış bilgisayarlarının ergonomik performansları değerlendirilmesi. Afyon Kocatepe Üniversitesi Fen ve Mühendislik Bilimleri Dergisi, 18, 169-177.

Sevinç, F. ve Özel, Ç.H. (2018). Boş zaman aktivitesi olarak dalış ve yaşam doyumu ile ilişkisi. Dokuz Eylül Üniversitesi Sosyal Bilimler Enstitüsü Dergisi, 20(3), 397-415.

Çulha, O. ve Gönül, E. (2019). Su altı dalış motivasyonu: Demografik ve deneyimsel özellikler bakımından değerlendirilmesi. Dokuz Eylül Üniversitesi Sosyal Bilimler Enstitüsü Dergisi, 21(4), 1271-1304.

Dağlığlu, T. ve Sürme, M. (2019). Su Altı dalış turizmi tercih nedenlerini belirlemeye yönelik bir araştırma. Akademik Araştırmalar ve Çalışmalar Dergisi, 11(21), 377-385. 
Doğru, H., Çelik, B. ve Yılmaz, B.S. (2019). Dalış turizmi emniyeti: Risk faktörleri ve çözüm önerileri. Anatolia: Turizm Araştırmaları Dergisi, 30(3), 185-197.

Ince, T. ve Bowen, D. (2011). Consumer satisfaction and services: insights from dive tourism. The Service Industries Journal, 31(11), 1769-1792.

Körpınar, Ş. (2019). Patent foramen ovale ve dalış. Bezmialem Science, 7(1), 5864.

Memişoğlu, M., Özyiğit, T., Şatır, S. ve Egi, S.M. (2019). Development of a Wireless Pressure Sensor Module to Convert the Mobile Phones into Dive Computers. S.Ü. Müh. Bilim ve Tekn. Derg., 7(2), 494-508.

Gülşahin, A., Cerim, H. ve Soykan, O. (2020). Su ürünleri mühendisliği'nde donanımlı dalışın iş sağlığı ve güvenliği açısından değerlendirilmesi. Düzce Üniversitesi Bilim ve Teknoloji Dergisi, 8, 94-101.

Höbek, A., Toklu, A.S., Balkis-Ozdelice, N. ve Alıçlı, B.N. (2020). Ölümcül dalış kazalarında boğulma derinliğinin belirlenmesinde planktonik organizmalar yardımcı olabilir mi? Adli Tip Bülteni, 25(1), 16-21.

Topcu, Ç. ve Genç, T.Ş. (2020). Türkiye'de Sualtı Araştırmalarında Bilimsel Dalış Yaklaşımı. Düzce Üniversitesi Bilim ve Teknoloji Dergisi. 8, 25552565.

https://divezone.net/best-dive-sites (erişim Temmuz 2021)

https://gezimanya.com/Yazilar/turkiyenin-en-iyi-dalis-bolgeleri (erişim Temmuz 2021)

https://medium.com/scubanomics/the-size-of-the-scuba-diving-industry-

573b8ac44c7c (erişim Temmuz 2021)

https://www.naui.org/ (erişim Temmuz 2021)

https://www.padi.com/courses?experience=continuing-education\&sort=popularity

(son erişim Temmuz 2021)

https://www.padi.com/sites/default/files/documents/2019-

02/2019\%20PADI\%20Worldwide\%20Statistics.pdf (erişim Temmuz 2021)

https://tssf.gov.tr/dalis-cankurtarma-uzman-egitim-merkezleril (erişim Temmuz 2021)

Kaynakça Bilgisi / Citation Information

Bozkurt, A. (2021). Türkiye'de aletli dalış konusunda son 20 yılda yazılan makalelerin alanyazın taraması. OPUS-Uluslararası Toplum Araştırmalar Dergisi, 18(44), 8280-8297. DOI: 10.26466/opus. 972132. 